\title{
Alice no País das Maravilhas e a importância do estudo da literatura inglesa infantil no desenvolvimento do ensino-aprendizagem da criança
}

\author{
Ana Paula Marinho Batista Coelho ${ }^{\mathrm{i}}$ \\ Giselda Maria Dutra Bandoliii \\ José Ignacio Ribeiro Marinho ${ }^{\text {iii }}$ \\ Joseani Adalemar Netto ${ }^{\text {iv }}$
}

\section{RESUMO}

O presente artigo pertence à área de Literaturas Estrangeiras Modernas e tem como principal objetivo uma discussão teórica no que tange à importância da leitura, da alfabetização, do letramento e da Literatura Inglesa na Educação Infantil para crianças na faixa etária entre 4/5 anos e 11 meses. Justifica-se pela importância de se olhar para a Educação Infantil como um processo de aprendizagens formais inseridas no todo da Educação Básica e está dividido em seções. A primeira seção aborda a importância da leitura, seja ela de Literatura Brasileira ou estrangeira, como uma aliada na aprendizagem do aluno. A segunda seção versa sobre a leitura como auxílio na aprendizagem da primeira infância. A terceira discute as diferenças entre alfabetização e letramento e, por fim, a quarta realiza a análise de algumas passagens da obra Alice no País das Maravilhas, de Lewis Carroll, e uma breve biografia do autor. O corpus teórico ancora-se em autores como Bagno (2009), Caligari (2002), Carroll (2012), Soares (1999, 2004, 2005), Souza (1995), Vigotski (2001), dentre outros.

Palavras-chave: Literatura Inglesa; Alfabetização; Letramento; Educação Infantil; Alice no País das Maravilhas.

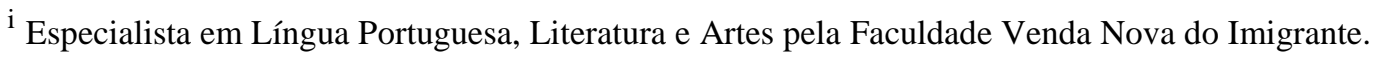
Graduada em Letras pela Faculdade de Filosofia, Ciências e Letras de Muriaé. Graduada em Normal Superior pela Faculdade de Educação Tecnológica do Estado do Rio de Janeiro. anacoelho.anacoelho@hotmail.com

ii Mestra em Cognição e Linguagem pela Universidade Estadual do Norte Fluminense Darcy Ribeiro. Especialista em Literatura Brasileira (Faculdade de Filosofia Ciências e Letras de Carangola) e em Língua Portuguesa (Faculdade de Filosofia de Itaperuna). Graduada em Letras pela Faculdade de Filosofia, Ciências e Letras de Carangola. | giseldabandoli@gmail.com

iii Mestrando em Letras pela Universidade Federal de Juiz de Fora. Especialista em Letras, Língua Latina e Filologia Românica e Literatura Contemporânea. Graduado em Letras pelo Centro Universitário São José de Itaperuna. | josebrenatti@ hotmail.com
}

${ }^{\text {iv }}$ Mestra e graduada em Letras pela Universidade Federal de Juiz de Fora. | joses27@yahoo.com.br 


\begin{abstract}
This article pertains to the area of Modern Foreign Literatures, proposing a theoretical discussion on the importance of reading, writing skills, literacy and English Literature in Early Childhood Education for children aged between 4/5 years and 11 months. This research is justified by the importance of looking at Early Childhood Education as a process of formal learning that is part of the whole of Basic Education. The paper is divided into four sections. The first one addresses the importance of the practice of reading, be it Brazilian or foreign literature, for the process of student learning. The second section deals with reading as an assistance in early childhood learning. The third one discusses the differences between reading and writing skills and literacy and, finally, the fourth one analyzes a few passages from Lewis Carroll's Alice in Wonderland and provides a brief biography of the author. The theoretical corpus is provided by authors such as Bagno (2009), Caligari (2002), Carroll (2012), Soares (1999, 2004, 2005), Souza (1995), Vigotski (2001), among others.
\end{abstract}

Keywords: English Literature; Reading and Writing Skills; Literacy; Early Childhood Education; Alice in Wonderland.

\title{
INTRODUÇÃO
}

A Educação brasileira sempre foi um tema para muitas discussões que se tornam ainda mais pertinentes para uma reflexão sobre sua qualidade em relação às novas necessidades que se fazem presentes na contemporaneidade. Com a inclusão da Educação Infantil no documento da Base Comum Curricular (BRASIL, 2017) um grande passo histórico para a integralidade da Educação Básica foi dado. Se antes a primeira infância na escola era vista como um momento restrito ao lúdico e ao cuidar, hoje é vista como um processo não só de socialização, mas de se pensar no universo de conhecimentos, experiências e habilidades que as crianças trazem para escola, vinculando a esse universo novas aprendizagens. As Diretrizes Curriculares Nacionais da Educação Infantil (DCNEI, Resolução CNE/CEB n 5/2009), em seu Artigo 4º, dizem que a criança é um cidadão com direitos e, em suas relações cotidianas, "constrói sua identidade pessoal e coletiva, brinca, imagina, fantasia, deseja, aprende, observa, experimenta, narra, questiona e constrói sentidos sobre a natureza e a sociedade, produzindo cultura" (BRASIL, 2009).

Sendo assim, busca-se discutir a importância da leitura, da alfabetização, do letramento e da Literatura Infantil Inglesa na grade curricular da Educação Infantil, da 
faixa etária dos 4 aos 5 anos e 11 meses. A BNCC (2017) sinaliza a relevância de um planejamento que sistematize os conhecimentos que se quer conceber às crianças nas interações com o mundo que as cerca. É preciso que o professor não enxergue a Educação Infantil como um processo trivial, corriqueiro e, sim, como um processo a ser pensado, organizado, refletido, como assinala bem o documento BNCC (2017):

\begin{abstract}
Essa intencionalidade consiste na organização e proposição, pelo educador, de experiências que permitam às crianças conhecer a si e ao outro e de conhecer e compreender as relações com a natureza, com a cultura e com a produção científica, que se traduzem nas práticas de cuidados pessoais (alimentar-se, vestir-se, higienizar-se), nas brincadeiras, nas experimentações com materiais variados, na aproximação com a literatura e no encontro com as pessoas. (BRASIL, 2017, p. 39)
\end{abstract}

A primeira seção deste artigo aborda a importância da leitura, seja ela de Literatura Brasileira ou estrangeira, como uma aliada na aprendizagem do aluno, visto que, na Educação Infantil, as crianças já demonstram curiosidade em relação aos materiais escritos de forma geral e, principalmente, em relação a livros de histórias. O quarto campo de experiências de que fala a BNCC (2017) relaciona-se com "a escuta, a fala, o pensamento e a imaginação" (BRASIL, 2017, p. 42), ou seja, a necessidade de expressão que as crianças têm latentes em si, como todo ser social:

\begin{abstract}
Na Educação Infantil, a imersão na cultura escrita deve partir do que as crianças conhecem e das curiosidades que deixam transparecer. As experiências com a literatura infantil, propostas pelo educador, mediador entre os textos e as crianças, contribuem para o desenvolvimento do gosto pela leitura, do estímulo à imaginação e da ampliação do conhecimento de mundo. Além disso, o contato com histórias, contos, fábulas, poemas, cordéis etc. propicia a familiaridade com livros, com diferentes gêneros literários, a diferenciação entre ilustrações e escrita, a aprendizagem da direção da escrita e as formas corretas de manipulação de livros. (BNCC, 2017, p. 42)
\end{abstract}

A escola, muitas vezes, não se prepara para estar alinhada aos campos de experiências que os documentos e diretrizes educacionais apontam e o professor, infelizmente, também enfrenta dificuldades com materiais de apoio ou mesmo com os meios que poderá usar para se aproximar e introduzir o hábito da leitura aos estudantes. A leitura precisa ser um momento de degustação do texto e das imagens, mas também ser pensada para além do prazer estético ou da fruição. É preciso que o professor esteja bem orientado para inserir a leitura em sua sala de aula, levando em consideração os 
saberes que poderão ser construídos a partir daquela leitura, do momento em que a atenção das crianças está voltada para a escuta da história a ser lida, tendo também o seu momento de fala, de interação em que o pensamento e a imaginação estarão construindo novos conhecimentos e ampliando seu repertório linguístico e literário.

A partir dessas primeiras reflexões, torna-se importante que o professor saiba as diferenças entre alfabetização e letramento, afinal de contas, ler não se limita apenas a decodificar a Língua, mas agregar a ela novos aprendizados. Nem sempre o currículo desenvolvido na escola abrange as orientações dadas pelos documentos oficiais de que dispõe nossa Educação e acaba por atrelar à escola, como seu principal dever, a alfabetização, e outros aspectos que envolvem a aprendizagem da Língua Materna, como o letramento literário, por exemplo, ficam em segundo plano.

Para se fazer uma reflexão mais consistente sobre as diferenças entre alfabetizar e letrar, a segunda seção deste trabalho não se furtará ao embasamento teórico que se faz necessário, pois não podemos apenas colocar a alfabetização e o letramento em polos opostos, afinal de contas, como nos diz Soares (2004, p. 8), os fenômenos alfabetização e letramento fundem-se e confundem-se. A autora diz que em outros países, como Estados Unidos e França, a discussão do termo letramento é à parte do termo alfabetização, não como ocorre no Brasil.

A terceira seção é o momento em que refletimos sobre a obra Alice no País das Maravilhas, de Lewis Carroll, no contexto da sala de aula da Educação Infantil. Evidentemente, a leitura da obra será feita a partir de uma adaptação para a Língua Portuguesa, pois não há indicativos, na BNCC, para se trabalhar textos de língua estrangeira. Porém, a história de Alice no País das Maravilhas tornou-se tão conhecida que já foi traduzida para vários idiomas, muitas produções cinematográficas já foram feitas e muitas crianças já conhecem a história por ter ouvido alguém contar ou ler para elas. Em todos os casos, trabalhar com a magia dessa ficção é ampliar não só o repertório linguístico dos alunos da Educação Infantil, mas também seu repertório literário, levando ao seu conhecimento um pouco sobre o autor e apresentando uma obra do cânone ocidental que introduz, já no século XIX, "a manipulação sistemática da imaginação, mesmo que aparentemente absurdo, como sistema. E de forma declarada, sem subterfúgios, como o haviam feito em alguns clássicos" (ARROYO, 2011, p. 22). Corresponde, assim, a um dos itens do quarto eixo que a BNCC (2017) aponta como 
importante no desenvolvimento da criança: a imaginação. O que parece absurdo no mundo real, transforma-se possível através da ficção e a criança ao perceber esse absurdo ressignifica o mundo e a realidade à sua volta.

Assim, entrelaçamos a importância da leitura no desenvolvimento infantil, contribuindo para a sua alfabetização e letramento, através de uma obra pertencente às Literaturas Estrangeiras Modernas, escrita em língua inglesa, colaborando para que o professor da Educação Infantil consiga olhar para a Literatura em sala de aula como uma possibilidade de construção de conhecimentos e de respeito às experiências da criança, ressignificando sua vivência para além da escola.

\section{A IMPORTÂNCIA DA LEITURA NA EDUCAÇÃO INFANTIL PARA O DESENVOLVIMENTO DO ENSINO E APRENDIZAGEM DA CRIANÇA}

A leitura é de suma importância em todas as idades, principalmente na infância, pois ela é fonte de conhecimento, estimulando a criatividade, assim como ativando o sensor crítico-reflexivo. É na infância que a personalidade é formada, logo, a leitura tem grande papel nisso. Conforme o minidicionário eletrônico Aurélio (2004), o termo "leitura", gramaticalmente um substantivo de gênero feminino, tem por significados: "1. Ato, arte ou hábito de ler, 2. Aquilo que se lê”. Acrescenta-se, ainda, a informação de que, consoante o dicionário eletrônico Houaiss (2009), "leitura" vem da língua latina, “lectura". De acordo com Maia (1998), a leitura é provedora de diversos tipos de conhecimentos, pois, com ela, o leitor informa-se sobre diversos assuntos, adquirindo vocabulários e facilidade na escrita.

[...] Ler é atribuir sentido; é ter concepção formulada sobre algo; é propor interpretação para uma obra; é decodificação de signos linguísticos. [...] A leitura faz-se conhecimento quando, além de compreender, interpreta-se. Além de interpretar, concebe e elabora conceitos sobre o que leu [...] (MAIA, 1998, s/p.)

Para que uma pessoa seja uma leitora ativa na vida adulta, precisa ser motivada na infância, seja por meio da escola, dos pais ou dos professores. Destaca-se, ainda, que a leitura é a interação entre o autor e o leitor. Assim sendo, frisa-se que cada leitor 
poderá realizar diversas interpretações sobre uma mesma obra, pois cada um possui uma imaginação única. Por isso, um dos papéis do professor é o de providenciar atividades de leitura, para ser ele o mediador entre o leitor e o texto - assim, é interessante que use textos que estejam de acordo com o contexto de mundo de cada turma.

$\mathrm{O}$ ato de contar uma história torna-se familiar ao aluno, pois corresponderá à voz do narrador, aquele que servirá como o elemento para prender a atenção do ouvinte. As crianças trazem consigo a oralidade, muitas vezes ouvem histórias contadas por seus familiares e a leitura na escola, mesmo em turmas em fase de alfabetização, consolidará o encontro entre o aluno e o texto. Há, sem dúvida, uma convivência natural do aluno com a oralidade de histórias em que o pensamento mágico é ali encontrado, a realidade e o imaginário caminham juntos.

Em conformidade com Kaufman (1995, p. 45), “para selecionar um texto, é necessário ter consciência de que os materiais devem estar relacionados à série correspondente". Souza (1995, p. 50-51) fala ainda sobre os inúmeros benefícios da leitura, como o estímulo das capacidades intelectuais, sendo que o leitor pode interpretar um livro à sua maneira, lendo; relendo; parando; e voltando atrás, ao seu próprio ritmo de leitura, ou apenas lendo as imagens e dando a elas valor de texto.

Na Educação, leis são aprovadas para que todos tenham acesso à escola, o que exige também programas e pedagogias que levem à alfabetização. Portanto, a leitura torna-se primordial tendo seu início logo na Educação Infantil. Antigamente, entre os séculos XVIII e XIX era difícil encontrar Literatura especificamente voltada para o público infanto-juvenil, então começa-se um movimento de adaptação de obras para que possam servir a esse público que ainda não estava incluso no movimento de leitura. Surgem as coletâneas de contos dos irmãos Grimm, por exemplo, além de várias outras adaptações que possam se transformar em leitura para crianças.

O livro Alice no País das Maravilhas (1865), escrito por Lewis Carroll, na Inglaterra, introduz para as crianças o maravilhoso que traduz simbolicamente as situações reais. Por ser, muitas vezes, até cômico, inesperado, seduz os pequenos para esse mundo de imaginação que tanto falamos quando nos referimos ao ato da leitura. Em consonância com Forteski, de Oliveira e Valério (2011, p. 121), "ler e escrever significam ir além da decifração de códigos, é ter-se a oportunidade de se tornar crítico para ser cidadão, comprometido com a realidade social”. 
Sublinha-se que quem tem o hábito de leitura tem a habilidade de raciocinar mais para além do ócio da televisão ou do celular, a título de exemplo. Acredita-se que essas pessoas sejam mais felizes, utilizando o próprio tempo de forma mais produtiva, além de terem mais facilidade em participar de conversas como debates de determinado assunto, pois, graças à leitura, elas sempre poderão estar a par de abordagens temáticas atuais, demonstrando mais capacidade intelectual.

O professor, poderá, a título de ilustração, usar das redes sociais digitais, como o Facebook, o Instagram, o Tumblr, o Twitter, o WhatsApp, o YouTube como ferramentas didático-pedagógicas, além de jogos e textos ou até produções cinematográficas adaptadas de obras de natureza literária para chamar a atenção do aluno para a leitura que se quer desenvolver. Ou seja, partindo do universo high tech a que o aluno já está acostumado, o professor consegue mostrar a ele que a ampliação de seu repertório de leitura e de mundo pode ser feito por meio de uma leitura mais densa, como uma obra literária.

Os pais têm uma grande função no desenvolvimento da leitura dos pequenos, pois quanto mais cedo eles lerem para os seus filhos, sejam contos, fábulas ou narrativas bíblicas ou heroicas, mais hábitos de leitura serão adquiridos. Destaca-se também a importância de que, além da leitura de textos de ordem literária, leiam bulas, enciclopédias, jornais, revistas, dentre outros.

Tendo a sala de aula como ambiente de construção e de consolidação do conhecimento, é fundamental que o professor utilize diversos gêneros não somente os literários para um melhor aprendizado e uma melhor inserção na cultura letrada. Levando-se em conta que a leitura é um ato social e os gêneros textuais, de toda espécie, devem ser apresentados aos alunos para que eles possam transitar de forma mais fluida nas esferas sociais. Os Parâmetros Curriculares Nacionais (BRASIL, 1998, p. 151-152) dizem exatamente isto:

[...] que é fundamental que a criança tenha experiência com textos de diferentes gêneros, com a função de construir um ambiente letrado, facilitando a observação de práticas sociais de escrita e de leitura. [...] "Nesse sentido, os textos de literatura geral e infantil, jornais, revistas, textos publicitários, entre outros, são os modelos que se podem oferecer às crianças para que aprendam sobre a linguagem que se usa para escrever. (BRASIL, 1998, p. 151-152) 
No dizer de Forteski, de Oliveira e de Valério "é essencial que a escola, mais que acumular conhecimento, ensine a raciocinar, desenvolva a criatividade, a imaginação e o espírito crítico e consiga entusiasmar o aluno para a aquisição do conhecimento. (2011, p. 122). Paulo Freire, em “A importância do ato de ler" (1989, p. 9), fala sobre a leitura que fazemos mecanicamente sem entender o real significado das palavras. Para ele, a prática de ler não está relacionada somente à leitura de um texto com base na interpretação da escrita e da linguagem: a prática de leitura é uma forma de conhecer o mundo.

Segundo o mestre, o primeiro passo para que a criança se torne um leitor é por meio do incentivo dos pais, em casa, para, quando chegar à escola, o professor dar continuidade ao processo, sendo que ele deve ser dinâmico perante os alunos, possibilitando a participação deles, evitando a memorização excessiva. Para Freire, a leitura é composta de interpretação, percepção crítica e reescrita do lido. $\mathrm{O}$ autor ressalta que não é necessária a memorização do objeto, mas sim puramente da apreensão do significado, e, em vista disso, ao apreender o significado sem a decoração excessiva, os alunos adquirirão o saber e, por conseguinte, o assunto será fixado na memória de forma livre.

A leitura literária na Educação Infantil é, não somente um instrumento pedagógico, mas também arte, interação com o mundo imaginário e real, são as palavras em função da criatividade, do jogo complexo da alma humana. Já na tenra idade a criança, através da leitura, busca ressignificar seu estar no mundo e suas relações com o outro, assim, encontrando-se em um universo que lhe é acolhedor. Só não podemos pensar na leitura como um instrumento moralizante ou simplesmente didático. Ela serve para inserir o aluno no mundo de relações sociais que exigirá dele proficiências e habilidades para conviver e superar suas dificuldades. Serve, ainda, para a construção de uma base sólida para outros níveis de compreensão e entendimento do mundo letrado e alfabetizado.

\section{ALFABETIZAÇÃO E LETRAMENTO DA CRIANÇA}


Conforme Soares e Batista (2005, p. 24), “chamamos de alfabetização o ensino e o aprendizado de uma outra tecnologia de representação da linguagem humana, a escrita alfabético-ortográfica". Inicialmente, assinala-se que alfabetização e letramento são palavras com definições distintas. O termo letramento não data de muito tempo, surgindo na década de 1980. Magda Soares (1999, p. 15), em seu livro Letramento: um tema em três gêneros, diz que quem o citou pela primeira vez foi Mary A. Kato, professora-titular do Departamento de Linguística da Pontifica Universidade Católica de São Paulo, no livro "No mundo da escrita - uma perspectiva psicolinguística" (1986).

Uma das primeiras ocorrências está em livro de Mary Kato, de 1986 (No mundo da escrita: uma perspectiva psicolinguística, Editora Ática): a autora, logo no início do livro (p. 7), diz acreditar que a língua falada culta "é consequência do letramento." (SOARES, 1999, n.p)

Alfabetização, em princípio, é o ato de ensinar a escrever e a ler. O letramento, em tese, seria quando se põe em prática o que aprendeu, justamente quando o educando se interessa pelas práticas sociais da escrita e da leitura. A definição que o minidicionário eletrônico Aurélio (2004) dá em relação à palavra letrado ratifica o conteúdo anterior: "capacitar ao uso social e cultural da leitura e da escrita".

De acordo com Vigotski (2001, p. 312-313), a criança, antes de passar pelo processo de ensino-aprendizagem da linguagem escrita, denomina-a como algo abstrato, dado que, acostumada com a linguagem oral, não sente utilidade ao uso dela. E a linguagem escrita é desprovida do aspecto entonacional, expressivo, musical e sonoro, sendo, portanto, uma linguagem de pensamento e de representação. Ou seja, a escrita é uma língua sem som, não-musical. Ainda em consonância com Vigotski (2001, p. 314315), quando o aluno inicia no processo de aprendizado da escrita, mesmo não sentindo necessidade dessa nova função de linguagem, tem uma noção extremamente vaga da utilidade dela.

Nas palavras de Soares e Batista (2005, p. 33-34), é muito comum que as crianças, mesmo depois de alfabetizadas, pensem que a grafia reproduz os sons da fala, como os exemplos por eles citados: "mati", no lugar de "mate", e "gatu", no lugar de 
"gato". Os Parâmetros Curriculares Nacionais de Língua Portuguesa explicam o que o professor deve ensinar no primeiro e segundo estágios escolares:

\begin{abstract}
Durante o primeiro estágio, previsto para durar em geral um ano, o professor deveria ensinar o sistema alfabético de escrita (a correspondência fonográfica) e algumas convenções ortográficas do português — o que garantiria ao aluno a possibilidade de ler e escrever por si mesmo, condição para poder disparar o segundo estágio do metafórico foguete. Esse segundo estágio se desenvolveria em duas linhas básicas: os exercícios de redação e os treinos ortográficos e gramaticais. (BRASIL, 1997, p. 27)
\end{abstract}

O objetivo da escola é formar leitores e, por que não, escritores. $\mathrm{O}$ aluno que lê diferentes gêneros literários terá mais facilidade ao redigir uma redação sobre qualquer abordagem temática proposta. A prática de leitura, por exemplo, ajuda a ampliar o vocabulário, corrige a ortografia e ajuda a ensinar a escrita de um texto coeso e coerente, "formar um leitor competente supõe formar alguém que compreenda o que lê; que possa aprender a ler também o que não está escrito, identificando elementos implícitos [...]" (BRASIL, 1997, p. 41).

Um leitor competente seria o leitor que lê e entende o que leu, não um leitor funcional. Contudo, averígua-se que o índice de analfabetismo funcional no Brasil é alarmante, infelizmente, e de modo geral é aquele em que o indivíduo reconhece letras e números, porém não consegue interpretar um texto simples, bem como operações matemáticas avançadas. No dizer de Luana Perez (2017), no artigo "Analfabetismo funcional", disponibilizado na revista on-line Brasil Escola, é fundamental o desenvolvimento de métodos que priorizem o letramento em vista da erradicação do analfabetismo funcional, um trabalho que deve ser feito tanto pelos professores quanto pelos pais.

\footnotetext{
Engana-se quem acredita que cabe somente à escola o papel de alfabetizar e letrar, visto que o letramento é uma prática presente em diversas situações do cotidiano, envolvendo não apenas a leitura tecnicista de textos, mas também o desenvolvimento da criticidade e capacidade de elaborar opiniões próprias diante dos conteúdos acessados. (PEREZ, 2017, n.p)
}

Assinala-se que um método utilizado ao longo dos anos, no ensinoaprendizagem da alfabetização, foi o das cartilhas - entretanto, destaca-se que elas foram perdendo espaço, deixando os professores à deriva dos livros didáticos recentes, 
publicados pelas editoras. Mesmo assim, nota-se, grosso modo, que o novo método ainda possui uma raiz nas antigas cartilhas. Para Gagliari (2002, p. 4), em consequência do fim do uso das cartilhas, o processo de alfabetização passou a ser uma responsabilidade direta do professor na sala de aula.

Conforme Soares, a palavra letramento derivou-se do inglês literacy, cuja etimologia originou-se do latim littera (letra) com o acréscimo do sufixo -cy. Ela diz que "letramento é, pois, o resultado da ação de ensinar ou de aprender a ler e a escrever, o estado ou a condição que adquire um grupo social ou um indivíduo como consequência de ter-se apropriado da escrita" (1999, p. 17). Uma pessoa considerada letrada, portanto, é aquela que põe em prática social o hábito da escrita e da leitura. Trata-se da sua inserção na cultura letrada.

Uma criança, antes de ser alfabetizada, incentivada ao mundo da leitura, adaptando-se e convivendo-se com esse meio, torna-se um indivíduo capaz de interagir de forma significativa em seu meio. Para que ela obtenha um sucesso mais concreto, recomenda-se que seja alfabetizada e letrada paralelamente. Ambiente escolar, livrarias, professores e, principalmente, os pais são alguns dos importantes aliados nesse processo.

Marcos Bagno (2009, p. 86), escritor, linguista e professor, afirma que "a grande tarefa da educação linguística contemporânea é desenvolver, incentivar e permitir a escrita e a leitura como peça-chave para a inserção no mundo letrado". Ao iniciar o processo de alfabetização, o professor deverá levar em conta o conhecimento de mundo que cada aluno traz, pois antes de ingressar na escola, o discente já é um falante ativo e nativo da língua - o meio social onde vive, seus costumes, dialetos, expressões, gírias que são, muitas vezes, taxadas como errados, na verdade, é na verdade uma variante linguística. Merecem destaque outros fatores referentes a isso: interesse, período de aprendizado e ritmo.

Em consonância com Bagno (2009, p. 73), “do ponto de vista da história de cada indivíduo, o aprendizado da língua falada sempre precede o aprendizado da língua escrita, quando ele acontece." Por isso, a escolha da história Alice no País das Maravilhas, para o segmento da Educação de crianças entre 4 e 5 anos e 11 meses de idade, concorre para que essas crianças tenham o contato com a literatura não somente 
de forma lúdica, mas com o interesse em ampliar seu repertório literário e, de certa forma, ajudá-las em seu processo de alfabetização.

Há palavras e momentos da história que podem ser recortados, após os momentos de leitura e interação, para que os alunos possam reconhecer palavras, letras usando, principalmente, as imagens e figuras que compõem o texto. A aprendizagem da leitura e o momento de alfabetização se interligam. Os elementos imagéticos se tornam relevantes para esse processo de reconhecimento figura/palavra. Aprender a ler tem a ver também com a memória visual. Vem daí a relevância das figuras que ajudam a contar a história. Uma obra literária para crianças precisa ter o cuidado com as imagens. Os pequenos leem as figuras como se estivessem lendo o texto escrito e essa coordenação entre figura e leitura é um elemento de imensa importância para o processo de alfabetização e letramento.

A leitura é fator prioritário, tanto das palavras quanto das imagens, principalmente em turmas que estão construindo um caminho para a alfabetização. É preciso que o professor, de acordo com o seu planejamento e objetivo, saiba em qual momento priorizar a leitura do texto escrito ou a leitura do texto imagético.

\section{ANÁLISE DE UMA NARRATIVA DA LITERATURA INGLESA: ALICE NO PAÍS DAS MARAVILHAS}

A grande e respeitada obra, Alice no País das Maravilhas, de título original Alice's Adventures in Wonderland, foi escrita pelo autor, fotógrafo e matemático, Lewis Carroll, pseudônimo de Charles Lutwidge Dogson. O livro, publicado em 1865, fez tanto sucesso, que Carroll escreveu a sequência, Alice no País do Espelho, cujo título original é Through the Looking-Glass, publicado em 1872. Os clássicos ocupam um lugar de muita importância e prestígio na tapeçaria da literatura inglesa, sendo adaptados para o cinema e o teatro desde 1903, ainda no cinema mudo.

Carroll, filho de um clérigo anglicano, nasceu no dia 27 de janeiro de 1832, em Daresbury, Cheshire, Inglaterra, e faleceu em 14 de janeiro de 1898, devido a uma pneumonia. Aos 20 anos, Carroll ganhou uma bolsa de estudos para a Christ College, em Oxford, onde mais tarde lecionou. Era muito tímido, porém tinha uma boa relação com as crianças. Destaca-se que Alice no País das Maravilhas foi inspirada na menina 
Alice Liddell, filha de seu amigo Henry George Liddell. Carroll tinha o costume de contar diversas histórias para Alice e suas irmãs e, em um dos passeios a barco, criou um poema em homenagem às três, que mais tarde, a pedido da própria Alice em escrevê-la em um livro, tornar-se-ia a sua maior obra: "e a história que povoou a imaginação das três meninas foi anotada, escrita e reescrita, depois publicada pelo reverendo em 1865, tornando-se um dos maiores clássicos da literatura de todos os tempos" (BRITO, 2008, p. 50).

Carroll não gostava de sua fama, não se sentia à vontade com ela e, em 1891, escreveu uma carta para sua amiga Anne Symonds, falando sobre isso e mostrando o seu lado mais tímido em relação ao seu sucesso, publicada no jornal americano The New York Times:

[...] All of that sort of publicity leads to strangers hearing of my real name in connection with the books, and tom y being pointed out to and stared at by strangers and being treated as a "lion" [...] And I hate all of that so intensely that sometimes I almost wish I had never written any books at all. (SCHUESSLER, 2017) ${ }^{1}$

Os livros de Carroll possuem brincadeiras, piadas e trocadilhos para os leitores britânicos, de acordo com a época em que foram escritas, e, muitas vezes, somente apresentam sentindo na versão original. O uso de sua obra na Educação Infantil, como se propõe esse artigo, trabalha com traduções. É preciso escolher bem qual a tradução que será utilizada para que não se perca a essência da história contada por Lewis Carroll e também estar atento à qualidade das imagens que a compõem, pois de acordo com o objetivo do professor, a seleção das imagens bem feitas, atrativas, comporão a sequência didática que o docente deverá seguir para atingir seus objetivos.

O leitor identifica-se com uma história a partir do texto, que é o que sustentará a narrativa, mas as ilustrações são também importantes, pois haverá uma articulação entre texto e imagens. No livro de Carroll, imagem e texto caminham juntos na construção do mágico, do maravilhoso. O autor gostava do uso de símbolos, em que tudo tem um ou vários significados ocultos. Utilizava-se, em linhas gerais, de referências matemáticas, baseadas na lógica. Como a história se passa dentro de um sonho, não possui regras, onde tudo parece natural. A bem da verdade, utilizava o estilo nonsense, que, em inglês, significa "ausência de sentido", pois a obra possui aspectos fantásticos e mágicos. 
A obra pode ser lida por meio de duas possíveis visões: a infantil e a adulta. A infantil, grosso modo, é uma leitura superficial, no nível da imaginação, sem questionamentos ou reflexões profunda sobre o jogo que se faz entre símbolos e significados ocultos, porém, a leitura adulta possui uma visão mais ampla, entendendo os significados escritos de forma subtendida, decifrando o que o autor queria transmitir nas entrelinhas.

Devemos lembrar também que muitos personagens e episódios em Alice são resultado direto de trocadilhos e outros jogos linguísticos, e teriam assumido formas completamente diversas se Carroll estivesse escrevendo, digamos, em francês. (GARDNER apud CARROLL, 2013, ix)

Um exemplo de alusão à matemática e à lógica está no capítulo 7, "Um chá maluco", onde o escritor apresenta a "relação inversa" ou "função inversa", presente no conteúdo de Funções da Matemática: "Eu digo, [...] pelo menos... pelo menos eu penso o que digo... é a mesma coisa, não? Nem de longe é a mesma coisa!” [...] Seria como dizer que ‘vejo o que como' é a mesma coisa que ‘como o que vejo!” (CARROLL, 2013, p. 55).

É fundamental compreender que Carroll viveu no decorrer da Era Vitoriana, época da rigidez dos princípios moralistas e da solidez política, fazendo com que ele, em sua obra, criticasse a condição do indivíduo de sua época, devido às inúmeras exigências sociais e à opressão moralizadora, que era uma forma de "fuga" ou desabafo. Os acontecimentos do dia a dia, os costumes do autor, o período histórico, a religião, as figuras importantes e as pessoas do convívio eram base de inspiração, como a própria Alice.

Em As aventuras de Alice no país das maravilhas e Através do espelho e o que Alice encontrou por lá, Martin Gardner explica as alusões que o escritor fazia às suas personagens:

Como Homero, a Bíblia e todas as outras grandes obras de fantasia, os livros de Alice prestam-se facilmente a qualquer tipo de interpretação simbólica política, metafísica ou freudiana. [...] encontra em Alice uma história secreta das controvérsias religiosas da Inglaterra vitoriana. O pote de geleia de laranja, por exemplo, é um símbolo do protestantismo [...] A batalha entre os Cavaleiros Branco e Vermelho é o famoso embate de Thomas Huxley e o bispo Samuel Wilberforce. A Lagarta Azul é Benjamin Jowett, a Rainha Branca é o cardeal John Henry Newman, a Rainha Vermelha é o cardeal Henry Manning, o Gato de Cheshire é o cardeal Nicholas Wiseman, e o 
Pargarávio "só pode ser uma medonha representação da visão britânica do papado [...]. (GARDNER apud CARROLL, 2013, viii)

A Literatura na Era Vitoriana retratava a moralidade e a submissão, ditando padrões fixos e pré-definidos. Muitos autores utilizavam a Literatura como forma de fuga da realidade social; porém, pode-se afirmar que nenhum foi mais engenhoso que Lewis Carroll, pois ele utilizou o pretexto, como marca estilística, de que a obra era um "sonho maluco", por isso, os acontecimentos em sua história eram mais "liberais", de acordo com o aceitável. Um exemplo é quando Alice desafia a Rainha Vermelha, no momento em que esta pergunta à Alice quem são os três jardineiros deitados em volta da roseira, no capítulo 8, "O campo de croqué da Rainha": “E quem são esses?' quis saber a Rainha apontando os três jardineiros [...] 'Como eu poderia saber?' disse Alice, surpresa com a própria coragem. 'Isso não é da minha conta."' (CARROLL, 2013, p. $65)$.

Morais (2004, p. 68) profere que: "O universo infantil era povoado por esses dois conceitos que, ao final, eram regidos por um único: medo. Medo da punição - uma das poucas certezas que aquele mundo apresentava". O livro de Carroll foge a esse padrão, pois nele Alice parte em uma aventura sem saber das consequências. É interessante mencionar que, na Época Vitoriana, as crianças eram criadas sabendo que poderiam ser punidas caso fizessem algo errado ou irresponsável, devido a tamanha rigidez. Eram esperados comportamentos de adultos pelos pais, comportamentos com os quais pessoas da sociedade inglesa se acostumaram. A ideia de culpa e de punição como consequência de más ações vistas pela sociedade opressiva, em que a ideia do prazer era vista como pecado.

Brito (2008, p. 51) desvenda alguns significados das passagens da obra. Por exemplo, um objeto bastante utilizado na Literatura Vitoriana era uma chave de ouro com a função de destrancar portas misteriosas, sendo que essa mesma porta dava para um jardim secreto. Conforme a autora, trata-se de uma metáfora do que poderia ser se ele tivesse certos "acessos", se a vida fosse diferente, ou seja, pode-se inferir que ele desejava que a menina Alice fosse adulta para se casar com ela, explicando porque no livro Alice tem constantes "mudanças" de tamanho.

Gardner (2013, x) comenta que o escritor, além de utilizar os acontecimentos como inspiração à sua obra, utilizou referências familiares, em que a Rainha de Copas e 
a Rainha Vermelha são criaturas más, representando o símbolo materno. Por sua vez, o Rei de Copas e o Rei Branco são símbolos paternos, criaturas boas. Contudo, todas essas alusões poderiam ser invertidas como em um espelho.

Todos os poemas contidos na obra são paródias de poemas famosos da época. "Em sua maioria, os poemas nos dois livros de Alice são paródias de poemas ou canções populares muito conhecidas pelos leitores contemporâneos de Carroll". (GARDNER apud CARROLL, 2013, p. 264). No capítulo 3, "Uma corrida em comitê e uma história comprida", Gardner (2013, p. 267) ressalta que a corrida em comitê simbolizaria os membros dos comitês que corriam em círculo, sem chegar a lugar algum, almejando um prêmio político. "O dedal, tomado de Alice e depois devolvido a ela, pode simbolizar o modo como os governos tomam dinheiro do bolso dos cidadãos e depois o devolvem na forma de projetos políticos" (GARDNER apud CARROLL, 2013, p. 268).

O chapeleiro era maluco, existia uma substância ao preparar o feltro, o mercúrio, chamado de mercurialismo, fazendo com que as vítimas desenvolvessem o "tremor do chapeleiro", afetando os olhos e os membros, tornando a fala confusa, e quando avançados os estágios, desenvolviam alucinações e outros sintomas psicóticos.

Algo interessante que mostra a mistura do que é realidade e do que é ficção no livro de Carroll e o liga à menina que o inspirou a escrevê-lo, é o mês e dia em que Alice encontra o País das Maravilhas. Não poderia ser coincidência que seja maio, dia 4, o mês e dia do aniversário da "Alice real". "Alice nasceu no dia 4 de maio de 1852" (GARDNER apud CARROLL, 2013, p. 287).

O contexto sócio-histórico-cultural, em que está inserido o autor Lewis Carroll, é um período de grandes avanços nos campos científico e tecnológico, bem como do surgimento de diferentes formas do pensamento filosófico, como o evolucionismo e o positivismo, ao mesmo tempo em que é uma época de moralidade puritana, rígida, que traçou um comportamento social marcado pelo radicalismo, no qual as bases eram as "grandes famílias em que o pai era uma espécie de chefe divino; e a mãe, uma criatura submissa" (BURGESS, 1996, p. 215).

Alice no País das Maravilhas contém um rol de elementos inerentes a um universo onde figuram o fantástico e o imaginário. Ademais, conta com elementos narrativos de importância para a ampliação da compreensão de uma narrativa por parte do aluno: enredo, narrador, personagens e ponto de vista. 
Uma narrativa maravilhosa, mesmo que pequena em extensão, possui um clímax ou desfecho, ou seja, é uma narrativa objetiva, em que o autor deverá finalizar a história em poucas páginas. Adiciona-se, também, elementos que costumam ser tão necessários: introdução, desenvolvimento e clímax. Possui diálogos, divididos em direto, indireto e indireto livre.

Conforme defendido por Soares (2009, p. 25-26), o conto e o romance são gêneros similares, com muitas características em comum, como a figura de um narrador, o enredo, porém, enquanto no romance o autor tem a possibilidade de desenvolver uma narrativa maior, no conto ele precisa fazer um resumo, uma economia nos meios de expressão.

Mesmo que a criança não saiba distinguir um conto de um romance, a Literatura na grade curricular é de imensa importância para essa criança. Tanto a Literatura de Língua Inglesa quanto a Literatura Brasileira poderão abrir horizontes, despertar interesses em outros gêneros, fazendo com que o aluno se apaixone por outra cultura e por outro idioma, fazendo com que demonstre desejos de ler cada vez mais, abrindo-se um leque maior de opções para o conhecimento de outros mundos, além daquele onde está inserido.

\section{CONSIDERAÇÕES FINAIS}

O delinear crítico-reflexivo feito neste artigo, ancorado em autores relevantes para o estudo sobre leitura, letramento e alfabetização, assume a postura da importância de se inserir a Literatura Inglesa infantil na Educação Infantil. Por meio dela, o professor influenciará não só no hábito de leitura nacional, como apresentará aos educandos literaturas feitas em outros países e que poderão preencher as aulas tornandoas mais atrativas, podendo o aluno se interessar pelo estudo da Língua Inglesa, por exemplo.

A interação em sala de aula mediada por um professor consciente de seu papel, promoverá o diálogo entre linguagens verbais e não verbais, já que o ensino e a aprendizagem são processos interativos e é preciso olhar para o contexto onde esse processo ocorre. No caso dessa reflexão, o contexto é a Educação Infantil, alunos entre 4 e 5 anos de idade, não sendo o do objetivo do professor ensinar a língua inglesa 
através da obra escolhida, mas mostrar às crianças, que além da Literatura feita em nosso país, por nossos autores nacionais, há também outros autores em outras localidades que se preocupam em criar histórias encantadoras e que podem trazer para sua vivência a ampliação de sua visão de mundo.

Ao se falar sobre Alfabetização, não pensaremos de modo fragmentado. Uniremos de forma significativa a alfabetização e o letramento que irão contribuir para toda a leitura que se pretende para a Educação Infantil, de acordo com o que nos dizem os documentos oficiais brasileiros e a partir das discussões fomentadas, há que se pensar a possibilidade de se trabalhar com a Literatura não só brasileira, mas estrangeira também, levando aos alunos novas perspectivas de leitura e compreensão.

Este artigo não traz uma receita ou uma sequência didática de como trabalhar a obra apresentada, Alice no País das Maravilhas, de Lewis Carroll, na Educação Infantil, mas discute a possibilidade de se pensar nesta obra e em outras da literatura estrangeira como um instrumento de trabalho com as crianças pequenas no que concerne à leitura. A criança geralmente sente-se parte do texto, navegando na história e em suas figuras para construir novos significados para o mundo e o ambiente que a cerca.

Espera-se que o professor, a partir dessas reflexões contribua para que a Literatura na escola seja mais do que apenas a apresentação historiográfica de momentos literários, mas da sua percepção como essencial na construção do ensino e da aprendizagem no que tange ao resgate da leitura significativa, sua compreensão, expressão e interação com o mundo ao redor. Cabe ao professor e à escola criarem espaço e condições para que a leitura e a alfabetização/letramento se façam de forma natural, desenvolvendo o gosto pela palavra escrita e desenvolvendo atividades que possibilitem a participação nesse universo ficcional, buscando uma postura mais crítica e autônoma do aluno-leitor.

\section{Referências}

ARROYO, Leonardo. Literatura Infantil Brasileira. $3^{\text {a }}$ Edição, São Paulo: Ed. Unesp, 2011.

BAGNO, Marcos. Preconceito Linguístico: o que é, como se faz. 52 $2^{\mathrm{a}}$ edição, São Paulo: Edições Loyola, 2009. 
BRASIL. Base Nacional Comum Curricular. Brasília: MEC, 2017. Disponível em: http://basenacionalcomum.mec.gov.br/images/BNC C_20dez_site.pdf. Acesso em: 18 de julho de 2020.

BRASIL. Ministério da Educação e do Desporto. Secretária de Educação Fundamental. Departamento da Educação Fundamental. Coordenação Geral de Educação Infantil. Referencial Curricular Nacional para a Educação Infantil: Conhecimento de Mundo. Brasília, 1998. V. 3, p. 151-152.

BRASIL. Ministério da Educação. CNE/CEB. Diretrizes Curriculares Nacionais para a Educação Infantil. Brasília, 1999.

BRASIL. Ministério da Educação. Conselho Nacional de Educação. Câmara De Educação Básica. Diretrizes Curriculares Nacionais Para a Educação Infantil. Resolução CNE/CEB 5/2009. Diário Oficial da União, Brasília, 18 de Dezembro de 2009b, Seção 1, P. 18.

BRASIL. Secretaria de Educação Fundamental. Parâmetros Curriculares Nacionais: língua portuguesa. Brasília: MEC/SEF, 1997.

BRITO, Aline Haiddé de. Análise interpretativa do romance Alice no país das maravilhas. Revista de Estudos Linguísticos e Literários, Patos de Minas: UNIPAM, 2008.

BURGESS, Anthony. A literatura inglesa. São Paulo: Ática, 1996.

CAGLIARI, Luiz Carlos. Alfabetização e ortografia. Literacy and orthografhy. Curitiba, Revista Científica Educar, Editora UFPR, 2002.

CARROLL, Lewis. As Aventuras de Alice no País das Maravilhas e Através do Espelho e o que Alice encontrou por lá - Edição Definitiva Comentada e Ilustrada. Introdução e notas Martin Gardner. Trad. Maria Luíza X. de A. Borges. Rio de Janeiro: Editora Jorge Zahar Editor Ltda., 2013.

CARROLL, Lewis. Biography.com. Disponível em: https://www.biography.com/people/lewis-carroll-9239598. Acesso em 12 de julho de 2020.

FERREIRA, Aurélio Buarque de Holanda. Miniaurélio Eletrônico. Minidicionário Eletrônico Aurélio. Editora Positivo Ltda, 2004. Versão 5.12.

FORTESKI, E.; OLIVEIRA, S. T. de; VALÉRIO, R, W. Prazer pela leitura: incentivo e o papel do professor. Ágora: Revista de Divulgação Científica, v. 18, n. 2, p. 120127, dez. 2011.

HOUAISS, Antônio. Houaiss Eletrônico. Editora Objetiva Ldta, 2009. Versão monousuário 3.0. 
KATO, Mary A. No mundo da escrita. Uma perspectiva sociolinguística. $4^{a}$ edição, São Paulo: Editora Ática, 1986.

KAUFMAN, Ana Maria. Escola, leitura e produção de textos. Porto Alegre: Artmed, 1995.

MAIA, Rita Maria de Abreu. Leitura e Conhecimento. Vértices, ano 1, n 2, nov. 1998.

MORAIS, Flávia Costa. Literatura vitoriana e educação moralizante. São Paulo: Alínea, 2004.

PEREZ, Luana Castro Alves. Analfabetismo funcional. Brasil Escola. Disponível em http://brasilescola.uol.com.br/gramatica/analfabetismo-funcional.htm. Acesso em $17 \mathrm{de}$ julho de 2020 .

SANTOS, Luciana Pereira dos; OLIVEIRA, Marcos Nonato de. Leituras e novas tecnologias: questões para a prática de ensino do professor de Língua Portuguesa. Disponível em: https://www.trabalhosfeitos.com/ensaios/Leitura-e-Novas-TecnologiasQuest\%C3\%B5es-Para/54476729.html. Acesso em 29 de julho de 2020.

SCHUESSLER, Jennifer. Fame-Hating Lewis Carroll Letter Lands in Los Angeles. The New York Times. Disponível em: https://artsbeat.blogs.nytimes.com/2014/04/17/famehating-lewis-carroll-letter-lands-in-los-angeles/?_php=true\&_type=blogs\&_r=0. Acesso em 12 de julho de 2020 .

SOARES, Magda Becker. Letramento e alfabetização: as muitas facetas. Revista Brasileira de Educação, 2004. Disponível em: https://www.scielo.br/pdf/rbedu/n25/n25a01.pdf. Acesso em 29 de julho de 2020.

SOARES, Magda Becker. Letramento: um tema em três gêneros. São Paulo: Autêntica, 1999.

SOARES, Magda Becker; BATISTA, Antônio Augusto Gomes. Alfabetização e Letramento: caderno do professor. Belo Horizonte: Centro de Alfabetização, Leitura e Escrita (Ceale)/Faculdade de Educação da UFMG, 2005. Disponível em: http://ceale.fae.ufmg.br/app/webroot/files/uploads/Col.\%20Alfabetiza\%C3\%A7\%C3\% A3o\%20e\%20Letramento/Col\%20Alf.Let.\%2001\%20Alfabetizacao_Letramento.pdf. Acesso em 29 de julho de 2020.

SOARES, Marcos. Literatura em Língua Inglesa: Tendências Contemporâneas, Curitiba: IESDE Brasil S. A., 2009.

SOUZA, Renata Junqueira de. Narrativas Infantis: a Literatura e a Televisão de que as crianças gostam - Considerações sobre os resultados de uma pesquisa. Revista Nuances, v. I, n. 1, p. 50-51, set. 1995.

VIGOTSKI, L. S. A construção do pensamento e da linguagem. Trad. Paulo Bezerra. São Paulo: Martins Fontes, 2001. 
Ana Paula Marinho Batista Coelho, Giselda Maria Dutra Bandoli, José Ignacio Ribeiro Marinho e Joseani Adalemar Netto.

Recebido em: 09/01/2020

Aceito em: 10/07/2020

1 “[...] Todo esse tipo de publicidade leva a estranhos ouvindo meu nome real em conexão com os livros, e sendo apontados e vistos por estranhos e sendo tratados como um 'leão' [...] E odeio tudo isso com tanta intensidade que às vezes quase desejo nunca ter escrito nenhum livro." 